\title{
Effects and mechanism of aromatic aminoketone SY0916 on osteoclastic bone destruction
}

\author{
Lin WANG, Shan-ying PENG, Yang LIU, Ping LI, Wen-jie WANG* \\ Department of Pharmacology, Institute of Materia Medica, Chinese Academy of Medical Sciences, Peking Union Medical College, \\ Beijing 100050, China
}

\begin{abstract}
Aim: To study the effects and mechanism of aromatic aminoketone (SY0916) on bone destruction in vitro. Methods: MC3T3-E1 cells and bone marrow cells were co-cultured to obtain purified osteoclasts. The proliferation of osteoclast-like cells (OCLs) was determined by MTT assay. The number of osteoclasts was measured by tartrate-resistant acid phosphatase (TRAP) staining. The functioning of osteoclasts was determined by measuring the area of bone resorption pits on bone slices. MMP- 9 secretion by osteoclasts was measured by an ELISA kit. Osteoclast apoptosis was detected by flow cytometry using an AnnexinV-FITC kit. Gene expression of RANK and MMP-9 in osteoclasts as well as RANKL and OPG in MC3T3-E1 cells was determined by real-time PCR. Results: SY0916 significantly inhibited the proliferation of OCLs, decreased both the total and average area of bone resorption pits, and dramatically inhibited the number of osteoclasts between concentrations of 0.01 and $10 \mu \mathrm{mol} / \mathrm{L}$. Furthermore, SY0916 reversed IL-1 $\beta$ mediated inhibition of osteoclast apoptosis and shortened osteoclast lifespan. In addition, SY0916 significantly inhibited the mRNA expression of RANK, RANKL, OPG, and MMP-9. However, the inhibition of OPG was weaker than that of RANKL. Accordingly, the ratio of RANKL to OPG mRNA expression in MC3T3-E1 cells was significantly decreased by SY0916. Meanwhile, the expression of MMP-9 protein in osteoclasts was inhibited by SY0916 between 0.01 and $10 \mu \mathrm{mol} / \mathrm{L}$.

Conclusion: SY0916 prevents osteoclastic bone destruction by inhibiting the proliferation and function of osteoclasts. The underlying mechanism for this effect involves the regulation of the RANKL-OPG-RANK axis, which determines the direction of bone metabolism.
\end{abstract}

Keywords: SY0916; osteoclast; bone destruction; RANKL; RANK; OPG

Acta Pharmacologica Sinica (2010) 31: 470-475; doi: 10.1038/aps.2009.202; published online 8 Mar 2010

\section{Introduction}

The destruction of bone and cartilage is the major cause of progressive disabilities culminating in the crippling of patients suffering from rheumatoid arthritis (RA). Extensive bone erosion is often seen as marginal joint erosions radiographically, and it is predictive of a poor prognosis. Prevention of the development of bone destruction is an important objective in the treatment of RA.

Osteoclasts are the cell type primarily responsible for resorption during both physiologic bone turnover and inflammatory bone disease ${ }^{[1]}$. They are formed by the fusion of mononuclear cells derived from osteoclast precursors. Bone-resorbing osteoclasts exhibit highly polarized morphological features such as actin rings, clear zones, and ruffled borders, which are markers of functional osteoclasts. The resorption lacuna is formed by targeted secretion of protons and proteases from

\footnotetext{
* To whom correspondence should be addressed. E-mail wwenj@imm.ac.cn

Received 2009-07-10 Accepted 2009-12-22
}

the ruffled border after tight attachment of osteoclasts to mineralized bone surfaces, which is mediated by integrin receptors expressed on the cell surface following polarization ${ }^{[2]}$. Multiple kinds of inflammatory cytokines are involved in the regulation of osteoclasts, including IL-1 $\beta$.

Aromatic aminoketone (SY0916) had been demonstrated to be a new type of PAF receptor antagonist and is considered a novel anti-inflammation drug. The anti-inflammatory effects of SY0916 have been shown by our previous studies both in vivo and in vitro ${ }^{[3]}$. Notably, we found that SY0916 prevented bone erosion from occurring in CIA rats ${ }^{[4]}$. However, we did not study the mechanism underlying this effect of SY0916. The aim of the present study was to investigate the effects and mechanism of SY0916 on bone destruction in vitro.

\section{Materials and methods} Animals

Male C57BL/ 6 mice (H-2 ${ }^{\mathrm{d}}, 18 \pm 2 \mathrm{~g}, 6-8$ weeks old) were provided by the Experimental Animal Center, Chinese Academy of Medical Sciences \& Peking Union Medical College (SPF, 
certificate № SCXK2004-0001). All animals were housed in groups under a 12-h light/dark regime (lights on from 7:00 to $19: 00$ ) at $23 \pm 2{ }^{\circ} \mathrm{C}$ prior to the experiments, and were given standard laboratory chow and tap water ad libitum. All animal procedures were approved by the Institutional Animal Care and Use Committee before any actual experimentation began.

\section{Reagents}

Rh IL-1 $\beta$, M-CSF, and sRANKL were purchased from Peprotech. FITC-phalloidin, MTT, and 1,25-dihydroxyvitamin D3 were purchased from Sigma. ELISA kits for murine MMP-9 were from R\&D systems. aMEM and FCS were from Hyclon. TRIzol reagent was purchased from Promega. SYBR ${ }^{\circledR}$ PrimeScript ${ }^{\mathrm{TM}}$ RT-PCR kit was from Takara. Annexin V-FITC kit for apoptosis detection was from BAOSAI Reagent.

\section{Test compound}

SY0916 was synthesized as described previously ${ }^{[3]}$, its structure is shown in Figure 1. The purity was more than $99 \%$ upon HPLC analysis. SY0916 was prepared in a $0.01 \mathrm{~mol} / \mathrm{L}$ stock solution with DMSO and stored at $-20^{\circ} \mathrm{C}$. Before using, the stock solution was diluted to the appropriate concentration in aMEM.

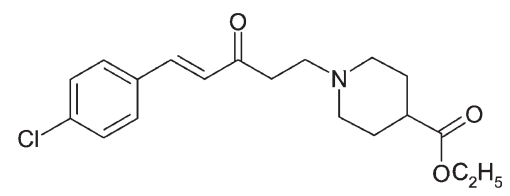

Figure 1. The structure of SY0916, $M_{\mathrm{w}}=386.31$.

\section{Cell culture}

The MC3T3-E1 cell line (an osteoblastic cell line derived from mice) was purchased from the cell center at the Chinese Academy of Medical Sciences \& Peking Union Medical College. MC3T3-E1 cells were cultured in aMEM containing 10\% FCS at $37{ }^{\circ} \mathrm{C}$ in $5 \% \mathrm{CO}_{2}$. When the cells were confluent (after approximately $3 \mathrm{~d}$ in culture), a mixture of $0.05 \%$ trypsin and $0.02 \%$ EDTA was used to passage the cells. The collected cells were then seeded on culture dishes.

\section{The preparation of bone marrow cells}

The femur and tibia were collected from 6-8 week-old C57BL/6 mice sacrificed under sterile conditions. A single cell suspension was prepared by gently pressing bone marrow segments through a glass injector. Bone marrow cells were separated from red blood cells by centrifugation at $790 \times g$ for $20 \mathrm{~min}$ in a Histpopaque 1077 centrifuge. The collected cells were washed twice and seeded on culture plates in aMEM containing $10 \% \mathrm{FCS}$ at $37{ }^{\circ} \mathrm{C}$ in $5 \% \mathrm{CO}_{2}$ for about $6 \mathrm{~h}$ and then collected.

\section{Induction and purification of osteoclasts}

MC3T3-E1 cells $\left(1 \times 10^{6}\right.$ cells $\left./ \mathrm{mL}\right)$ and bone marrow cells $\left(2 \times 10^{7}\right.$ cells $/ \mathrm{mL}$ ) were co-cultured in aMEM containing 10\% FCS in $100 \mathrm{~mm}$ tissue culture dishes $(15 \mathrm{~mL} /$ dish) precoated with 2.5 $\mathrm{mL}$ of $0.2 \%$ collagen gel matrix. After $2 \mathrm{~d}$, half of the medium was changed with fresh medium. Subsequently, 1,25-dihydroxyvitamin D3 $\left(10^{-8} \mathrm{~mol} / \mathrm{L}\right)$ and M-CSF $(50 \mathrm{ng} / \mathrm{mL})$ were added to the media as stimulants. After culturing for $5 \mathrm{~d}$, the non-adherent cells were removed and the mononuclear cells attached to the osteoblastic cell layer were recovered as pOCs by gentle pipetting with fresh aMEM. pOCs were collected by centrifugation $\left(110 \times g\right.$ for $5 \mathrm{~min}$ ) and $2 \times 10^{5}$ cells were placed in 48 well culture plates, which were then cultured with M-CSF $(50 \mathrm{ng} / \mathrm{mL})$ and sRANKL $(50 \mathrm{ng} / \mathrm{mL})^{[5]}$. OCLs were formed within $48 \mathrm{~h}$ of culturing, which then differentiated to osteoclasts after stimulation with sRANKL (100 ng/mL) for $24 \mathrm{~h}$.

\section{MTT assay for the proliferation of OCLs}

OCLs were placed in 96-well culture plates and pre-cultured for $4 \mathrm{~h}$. Then, the incubation continued for another $48 \mathrm{~h}$ with SY0916 at concentrations ranging from 0.01 to $10 \mu \mathrm{mol} / \mathrm{L}$. Proliferation of OCLs was determined by MTT assay. MTT was added to each well for $4 \mathrm{~h}$ before the addition of DMSO, and the absorbance value of each well was measured at 570 nm.

\section{Determination of the activity and function of osteoclasts}

Purified osteoclasts were obtained according to the method presented above. Sterile bone slices $\left(2 \mathrm{~cm}^{2}\right)$ and coverslips were pre-positioned in the plates. Except for the blank control group (without the addition of IL-1 $\beta)$, IL-1 $\beta(280 \mathrm{ng} / \mathrm{mL})$ was added into each group. SY0916 was added to experimental groups at concentrations ranging from 0.01 to $10 \mu \mathrm{mol} / \mathrm{L}$. After culturing for $3 \mathrm{~d}$, the coverslips were dislodged and the number of osteoclasts with more than three nuclei were measured by TRAP staining following the protocol provided by the TRAP staining kit (Sigma) ${ }^{[6]}$. Each group was divided in three parallel wells and five random fields were counted for each well. The bone slices were stained by toluidine blue as reported previously and the functioning of osteoclasts was determined by measuring the area of bone resorption pits. Images of osteoclasts and bone slices were captured by a digital camera. The osteoclast count and the bone lacuna area were analyzed by Image 5.0 software.

\section{ELISA method for MMP-9 expression assay}

Osteoclasts were placed in 48-well culture plates and precultured for $4 \mathrm{~h}$. Except for the blank control group (without the addition of IL-1 $\beta)$, IL-1 $\beta(280 \mathrm{ng} / \mathrm{mL})$ was added into each group and SY0916 (from 0.01 to $10 \mu \mathrm{mol} / \mathrm{L}$ ) was added to the experimental groups. Subsequently, all groups were incubated for $48 \mathrm{~h}$. Then, the cell supernatants were collected and the level of MMP-9 was measured by an ELISA kit according to the manufacturer's protocol.

Determination of osteoclasts apoptosis by AnnexinV-FITC kit Osteoclasts were placed in 48 well culture plates and precultured for $4 \mathrm{~h}$. Except for the blank control group (without 
the addition of IL-1 $\beta)$, IL- $1 \beta(280 \mathrm{ng} / \mathrm{mL})$ was added into each group and SY0916 (from 0.01 to $10 \mu \mathrm{mol} / \mathrm{L}$ ) was added to the experimental groups. All groups were incubated for $72 \mathrm{~h}$. The cells were washed twice with cold PBS and resuspended in $1 \times$ binding buffer at a concentration of $1 \times 10^{6}$ cells $/ \mathrm{mL}$. Subsequently, $100 \mu \mathrm{L}$ of cell suspension was transferred to a $5-\mathrm{mL}$ culture tube. Ten $\mu \mathrm{L}$ of Annexin V-FITC and $5 \mu \mathrm{L}$ of PI were added to the cell suspension ${ }^{[7]}$. The tube was vortexed gently and incubated for $30 \mathrm{~min}$ at room temperature $\left(20-25^{\circ} \mathrm{C}\right)$ in the dark. Then, $400 \mu \mathrm{L}$ of $1 \times$ binding buffer was added into each tube. The cells were immediately analyzed by flow cytometry.

\section{Real-time PCR for RANK, RANKL, OPG, and MMP-9 gene expres- sion}

Except for the blank control group (without the addition of IL-1 $\beta)$, IL-1 $\beta$ (280 $\mathrm{ng} / \mathrm{mL}$ ) was added into each group and SY0916 (from 0.01 to $10 \mu \mathrm{mol} / \mathrm{L}$ ) was added to the experimental groups. All groups were incubated for $15 \mathrm{~h}$. To detect the mRNA expression of RANK and MMP-9, total cellular RNA was extracted from $1 \times 10^{5}$ osteoclasts. To detect the mRNA expression of RANKL and OPG, total cellular RNA was extracted from $5 \times 10^{6}$ MC3T3-E1 cells stimulated with IL-1 $\beta$. The RNA was extracted with TRIzol according to a previously reported method ${ }^{[8]}$. DNA synthesis was performed following the protocol of the SYBR ${ }^{\circledast}$ PrimeScript ${ }^{\mathrm{TM}}$ RT-PCR kit. Realtime PCR for $\beta$-actin, RANKL, OPG, RANK, and MMP-9 was performed in triplicate following the manufacturer's protocol. The samples were placed into 8 stripe tubes (Axygen). PCR amplifications were performed using the ABI PRISM 7000HT Real-Time PCR system. Thermal cycling conditions were $30 \mathrm{~s}$ at $95^{\circ} \mathrm{C}, 40$ cycles of $5 \mathrm{~s}$ at $95^{\circ} \mathrm{C}$ and $31 \mathrm{~s}$ at $60^{\circ} \mathrm{C}$. The primers used for the reaction are shown in Table 1. Gene expression was measured by relative quantitation ${ }^{[9]}$, which compared the threshold cycles $(\mathrm{Ct})$ of the sample of interest to the $\mathrm{Ct}$ generated by a reference sample that was referred to as the calibrator (non-stimulated cells that were incubated for the same time period as cells in the experimental groups). Gene expression was normalized to $\beta$-actin expression by subtraction of $\mathrm{Ct}$ to provide $\Delta \mathrm{Ct}$ values. The $\Delta \Delta \mathrm{Ct}$ was calculated as the difference

Table 1. Primer sequences used in real-time RT-PCR.

\begin{tabular}{|c|c|c|c|}
\hline Gene & & Primers & $\begin{array}{l}\text { Product } \\
\text { (bp) }\end{array}$ \\
\hline RANK & $\begin{array}{l}\text { sense } \\
\text { anti-sense }\end{array}$ & $\begin{array}{l}\text { 5'-ATG GTG GGC TAC CCA GGT GA-3' } \\
\text { e } \text { 5'-ACT TGC GGC TGC ACA GTG A-3' }^{\prime}\end{array}$ & 150 \\
\hline MMP-9 & $\begin{array}{l}\text { sense } \\
\text { anti-sense }\end{array}$ & $\begin{aligned} & \text { 5'-GGT GTA GCA CAA CAG CTG ACT ACG A-3 } \\
\text { e } & 5^{\prime} \text {-GAG CGG CCC TCA AAG ATG AA-3' }\end{aligned}$ & $3^{\prime} 130$ \\
\hline$\beta$-actin & $\begin{array}{l}\text { sense } \\
\text { anti-sense }\end{array}$ & $\begin{array}{l}\text { 5'-CAT CCG TAA AGA CCT CTA TGC CAA C-3' } \\
\text { e } \text { 5'-ATG GAG CCA CCG ATC CAC A-3' }^{\prime}\end{array}$ & $3^{\prime} 171$ \\
\hline RANKL & $\begin{array}{l}\text { sense } \\
\text { anti-sense }\end{array}$ & $\begin{array}{l}\text { 5'-CAT GTG CCA CTG AGA ACC TTG AA-3' } \\
\text { e 5'-CAG GTC CCA GCG CAA TGT AAC-3' }\end{array}$ & 107 \\
\hline$O P G$ & $\begin{array}{l}\text { sense } \\
\text { anti-sense }\end{array}$ & $\begin{aligned} & \text { 5'-CAA TGG CTG GCT TGG TTT CAT AG-3' } \\
\text { e } & \text { 5'-CTG AAC CAG ACA TGA CAG CTG GA-3' }\end{aligned}$ & 118 \\
\hline
\end{tabular}

between $\Delta \mathrm{Ct}$ values for IL-1 $\beta$-stimulated and non-stimulated cells. The relative difference in the expression of the gene of interest between stimulated and unstimulated cells was determined using the equation of $2^{-\Delta \Lambda C t}$. This equation was considered valid only if the amplification efficiencies of the gene of interest and $\beta$-actin were approximately equal. To confirm the validity of the method, we performed the reaction over a range of DNA template concentrations and the resulting slope of the log of the template DNA concentration plotted against the $\Delta \mathrm{Ct}$ calculated for $\beta$-actin and each gene of interest was less than 0.1 (data not shown).

\section{Statistical method for analysis}

All values were expressed as the mean $\pm S D$ of at least three independent experiments. Statistical analysis was carried out using SPSS-13.0 software. One-way ANOVA with post hoc analysis by an LSD test or by the Dunnett's C test was applied, which compared treatment groups to a specific control group. A value of $P<0.05$ was considered statistically significant.

\section{Results}

The effect of SY0916 on the proliferation of OCLs

The proliferation of OCLs was significantly decreased by SY0916 between 0.01 and $10 \mu \mathrm{mol} / \mathrm{L}$. The value of OD: $0.40 \pm 0.07(0.01 \mu \mathrm{mol} / \mathrm{L}), 0.30 \pm 0.08^{\mathrm{b}}(0.1 \mu \mathrm{mol} / \mathrm{L}), 0.39 \pm 0.06^{\mathrm{b}}$ $(1 \mu \mathrm{mol} / \mathrm{L}), 0.31 \pm 0.09^{\mathrm{b}}(10 \mu \mathrm{mol} / \mathrm{L}), 0.48 \pm 0.05$ (control), $n=5$, ${ }^{\mathrm{b}} P<0.05$ vs control group.

\section{The effect of SY0916 on the activity and function of osteoclasts}

IL-1 $\beta$ significantly increased the number of osteoclasts and bone resorption pits. Typical photos of osteoclasts stained by TRAP and bone slices stained by toluidine are shown in Figure 2. IL-1 $\beta$ also increased the total area and average area of bone resorption pits, which was in accordance with previous reports ${ }^{[10,11]}$. SY0916 significantly decreased both the total area and average area of bone resorption pits at concentrations ranging from 0.01 to $10 \mu \mathrm{mol} / \mathrm{L}$. In addition, SY0916 also inhibited the number of osteoclasts at $0.01-10 \mu \mathrm{mol} / \mathrm{L}$ (Table 2).

The effect of SY0916 on the MMP-9 secretion of osteoclasts The level of MMP-9 in osteoclasts increased approximately 2 -fold after stimulation with IL-1 $\beta$ for $48 \mathrm{~h}$. The increase in MMP-9 was also observed in osteoclasts after stimulation with IL-1 $\beta$ for $24 \mathrm{~h}$, but it was not a significant difference. SY0916 notably inhibited the expression of MMP-9 in osteoclasts stimulated by IL-1 $\beta$ at $0.1-10 \mu \mathrm{mol} / \mathrm{L}$ (Figure 3).

\section{The effect of SY0916 on the apoptosis of osteoclasts}

Under normal conditions, osteoclasts extensively undergo apoptosis after five days in culture. However, IL- $1 \beta$ inhibited the apoptosis of osteoclasts and extended their lifespan. SY0916 significantly blocked the effect of IL-1 $\beta$ at $0.01-10$ $\mathrm{mmol} / \mathrm{L}$ (Figure 4). 
A

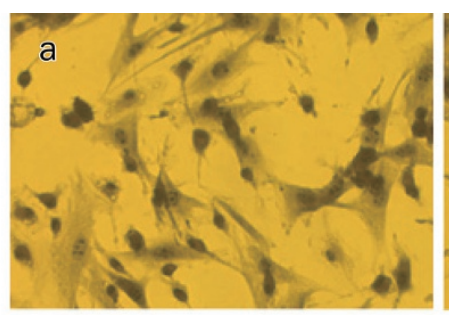

B

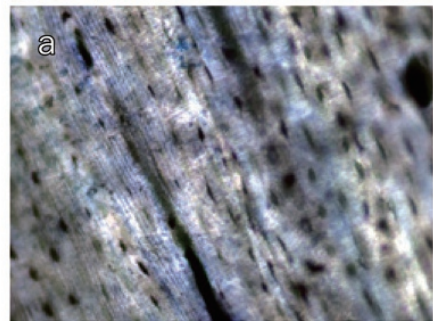

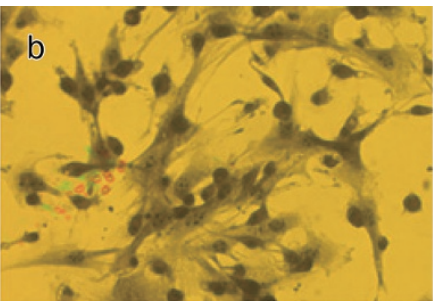
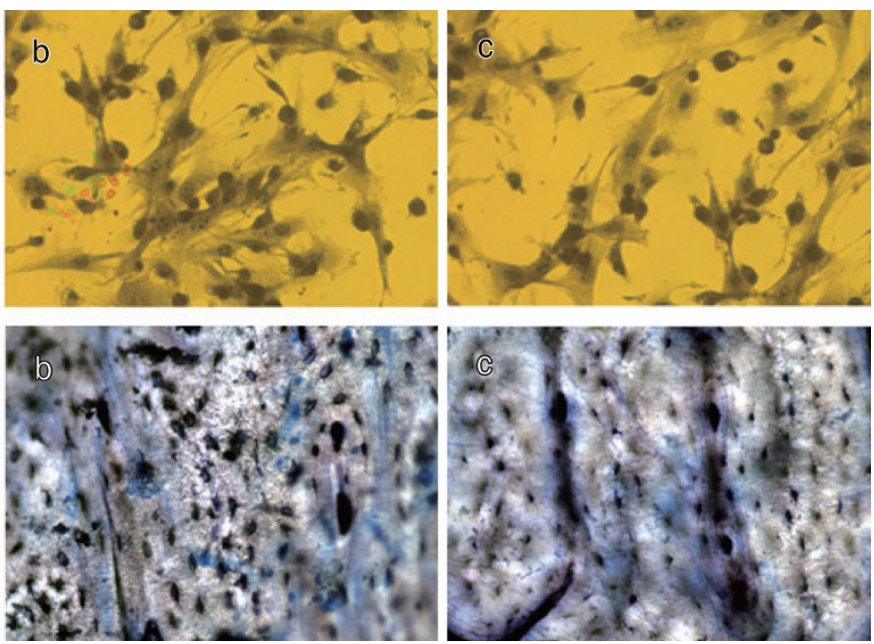

Figure 2. The photographs of osteoclasts stained by TRAP and bone resorption pits stained by toluidine blue. Sterile bone slices $\left(2\right.$-cm $\left.{ }^{2}\right)$ and coverslips were pre-positioned in the plates. Except for the blank control group (without the stimulator of IL-1ß), IL-1ß $(280 \mathrm{ng} / \mathrm{mL}$ ) was added into each group and SY0916 at 0.01-10 $\mathrm{mmol} / \mathrm{L}$ were added into the experimental groups. After being cultured for $3 \mathrm{~d}$, osteoclasts were measured by TRAP staining. The bone slices were stained by toluidine blue. Images of osteoclasts and bone slices were captured by the digital camera of the microscope. (A) The typical photographs of the osteoclasts (TRAP stain, $\times 400$ ). (B) The typical photographs of bone slices (toluidine blue stain, $\times 400$ ). a: blank control group; b: IL$1 \beta$ stimulated group; c: SY0916 $10 \mu \mathrm{mol} /$ Lgroup.

Table 2. Effect of SY0916 on the activity and function of osteoclasts. Except for the blank control group (without the stimulator of IL-1 $\beta$ ), IL-1 $\beta$ ( 280 $\mathrm{ng} / \mathrm{mL}$ ) was added into each group and SY0916 at 0.01-10 $\mu \mathrm{mol} / \mathrm{L}$ were added into the experimental groups. After culturing for $3 \mathrm{~d}$, the coverslips were dislodged and the number of osteoclasts with more than three nuclei was measured. The function of osteoclasts was determined by measuring the number and area of bone resorption pits. Images of osteoclasts and bone slices were captured on the digital camera and analyzed by Image 5.0 software. Values were expressed as mean \pm SD. $n=5$. ${ }^{\mathrm{b}} P<0.05$ vs blank control group. ${ }^{\mathrm{e}} P<0.05$ vs IL-1 $\beta$ group.

\begin{tabular}{lcccc}
\hline \multicolumn{1}{c}{ Group } & $\begin{array}{c}\text { The number of } \\
\text { osteoclasts (counts/field) }\end{array}$ & $\begin{array}{c}\text { Bone reporption pits } \\
\text { (counts/field) }\end{array}$ & $\begin{array}{c}\text { Average area of pits } \\
\text { (area/pit) }\end{array}$ & $\begin{array}{c}\text { Total area of pits } \\
\text { (area/field) }\end{array}$ \\
\hline Control & $13 \pm 2$ & $11 \pm 2$ & $1798 \pm 773$ & $19906 \pm 2496$ \\
IL-1B & $22 \pm 3^{\mathrm{b}}$ & $56 \pm 1^{\mathrm{b}}$ & $3679 \pm 928^{\mathrm{b}}$ & $95427 \pm 12640^{\mathrm{b}}$ \\
SY0916 $0.01 \mu \mathrm{mol} / \mathrm{L}$ & $11 \pm 2^{\mathrm{e}}$ & $34 \pm 10^{\mathrm{e}}$ & $1950 \pm 1071^{\mathrm{e}}$ & $57409 \pm 10301^{\mathrm{e}}$ \\
SY0916 $0.1 \mu \mathrm{mol} / \mathrm{L}$ & $8 \pm 0^{\mathrm{e}}$ & $32 \pm 13^{\mathrm{e}}$ & $1675 \pm 127^{\mathrm{e}}$ & $48318 \pm 3020^{\mathrm{e}}$ \\
SY0916 $1 \mu \mathrm{mol} / \mathrm{L}$ & $8 \pm 1^{\mathrm{e}}$ & $22 \pm 6^{\mathrm{e}}$ & $1596 \pm 145^{\mathrm{e}}$ & $44295 \pm 17995^{\mathrm{e}}$ \\
SY0916 $10 \mu \mathrm{mol} / \mathrm{L}$ & $8 \pm 1^{\mathrm{e}}$ & $19 \pm 8^{\mathrm{e}}$ & $1464 \pm 149^{\mathrm{e}}$ & $33644 \pm 7221^{\mathrm{e}}$ \\
\hline
\end{tabular}

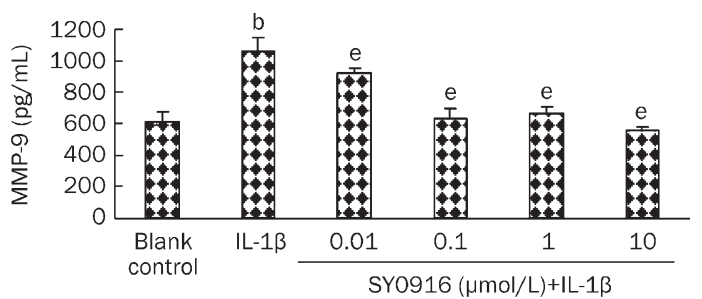

Figure 3. Effect of SY0916 on the secretion of MMP-9 in osteoclasts. Osteoclasts were placed on the 48-well culture plates and pre-cultured for $4 \mathrm{~h}$. Except for the blank control group (without the stimulator of $\mathrm{IL}-1 \beta), \mathrm{IL}-1 \beta(280 \mathrm{ng} / \mathrm{mL})$ was added into each group and SY0916 at $0.01-10 \mu \mathrm{mol} / \mathrm{L}$ were added int o the experimental groups. Then the incubation continued for another $48 \mathrm{~h}$. The cell supernatants were collected and the level of MMP-9 was measured by ELISA kit according to the manufacturer's protocol. Values were expressed as mean \pm SD. $n=3$. ${ }^{\mathrm{b}} P<0.05$ vs blank control group. ${ }^{\mathrm{e}} P<0.05$ vs IL-1 $\beta$ group.
The effect of SY0916 on the gene expression of RANK, RANKL, OPG, and MMP-9

IL-1 $\beta$ significantly increased the mRNA expression of RANK, RANKL, OPG, and MMP-9. IL-1 $\beta$ stimulation increased the mRNA expression of RANKL and OPG by approximately 6-fold and 2-fold, respectively, which caused the ratio of RANKL to OPG to significantly increase in MC3T3-E1 cells. SY0916 between 0.01 and $10 \mu \mathrm{mol} / \mathrm{L}$ significantly inhibited the mRNA expression of MMP-9 and RANK in osteoclasts. In addition, SY0916 inhibited the expression of RANKL and $O P G$ in MC3T3-E1 cells, whereas the inhibition of the OPG gene was weaker. As a result, the ratio of RANKL to OPG in MC3T3-E1 cells was significantly decreased (Figure 5A-5B).

\section{Discussion}

SY0916 was developed as a novel type of anti-inflammatory 

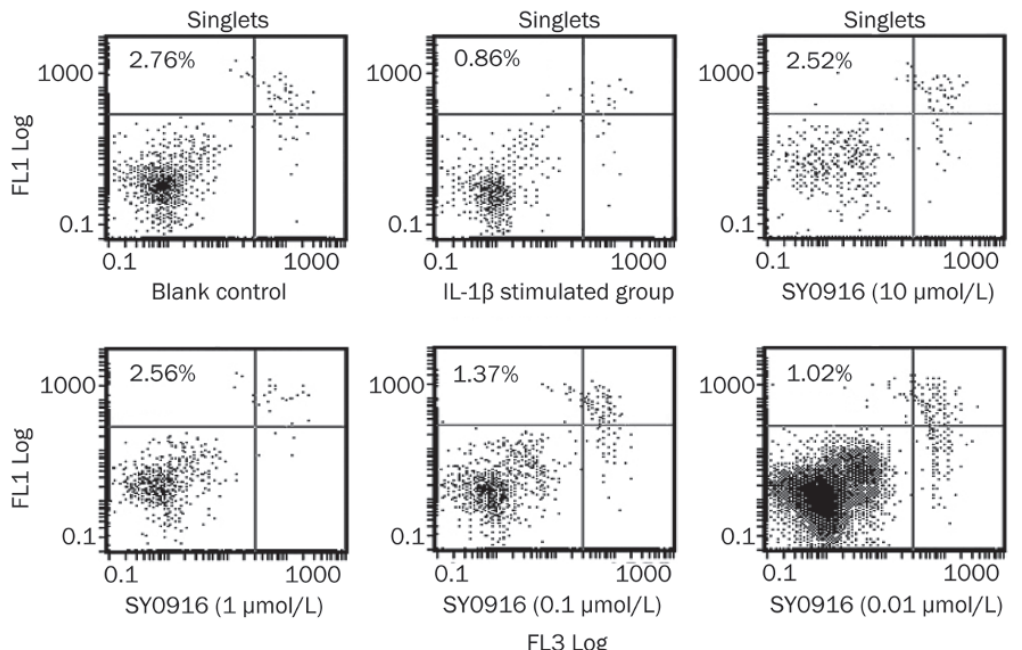

Figure 4. Effect of SY0916 on the apoptosis of osteoclasts. Except for the blank control group (without the stimulator of $\mathrm{IL}-1 \beta), \mathrm{IL}-1 \beta(280 \mathrm{ng} / \mathrm{mL})$ was added into each group and SY0916 at 0.01-10 $\mu \mathrm{mol} / \mathrm{L}$ were added into the experimental groups. After being cultured, the cells were resuspend in $1 \times$ Binding Buffer at a concentration of $1 \times 10^{6}$ cells $/ \mathrm{mL} .100$ $\mu \mathrm{L}\left(1 \times 10^{5}\right.$ cells $)$ was transfered into a $5 \mathrm{~mL}$ culture tube, then added $10 \mu \mathrm{L}$ of Annexin V-FITC and $5 \mu \mathrm{L}$ of PI. The tubes were gently vortexed and incubated for $30 \mathrm{~min}$ at room temperature in dark. Four hundred $\mu \mathrm{L}$ of $1 \times$ Binding Buffer was added into each tube. All samples were analyzed on a FACS flow cytometry (EPICS XLHP). Apoptotic cells, viable cells and necrotic cells were detected as $\mathrm{An}^{+} / \mathrm{PI}^{-}$cells, $\mathrm{An}^{-} / \mathrm{PI}^{-}$cells and $\mathrm{PI}^{+}$cells, respectively. The $\mathrm{An}^{+} / \mathrm{PI}^{-}$cells represent the annexin- $V$ positive and propidium iodide negative cells, that is, the apoptosis cells. The experiment was repeated three times and the typical result was presented.
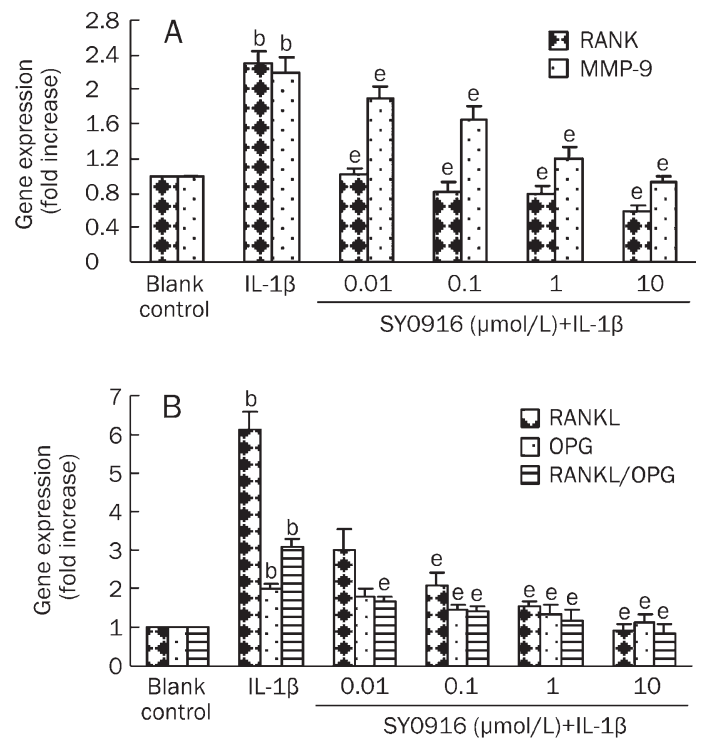

Figure 5. Effect of SY0916 on gene expression of RANKL and OPG in MC3T3-E1 cells and gene expression of RANK and MMP-9 in osteoclasts. SYBR $^{\circledast}$ PrimeScript ${ }^{\mathrm{TM}}$ RT-PCR kit was applied for cDNA synthesis and realtime PCR for $\beta$-actin, RANKL, OPG, RANK, MMP-9. The detection was performed in triplicate following the protocol of the kit. Gene expression was measured by relative quantitation. The relative difference in the genes of interest expression between stimulated and unstimulated cells was determined using the equation of $2^{-\Delta \Delta C t}$. Results were expressed as fold increase in gene expression by IL-1 $\beta$ stimulated cells compared to unstimulated (media alone) cells. The y-axis showed the means of $2^{-\Delta \Delta C t}$ of each group, which reflected the fold increase in the genes of interest expression. The $\mathrm{x}$-axis showed the treatment given to each group. (A) Effect of SY0916 on the gene expression of RANK and MMP-9 in osteoclasts; (B) Effect of SY0916 on the gene expression of RANKL and OPG in MC3T3-E1 cells. ${ }^{\mathrm{b}} P<0.05$ vs blank control, ${ }^{\mathrm{e}} P<0.05$ vs IL- $1 \beta$.

drug. In a previous pharmacodynamic study, Wang et al found that SY0916 treatment had a beneficial effect in CIA rats, especially in preventing bone erosion in this mode ${ }^{[4]}$. However, little was known about the mechanism underlying the compound's effect on bone protection.

Osteoclasts, the only somatic cells with bone-resorbing capacity, play a critical role in the pathogenesis of bone destructive disorders such as rheumatoid arthritis and osteoporosis $^{[12]}$. Therefore, osteoclasts were chosen as the study targets for this research. The present study showed that SY0916 concentrations from 0.1 to $10 \mu \mathrm{mol} / \mathrm{L}$ could significantly inhibit the proliferative and functional responses of osteoclasts stimulated by IL-1 $\beta$. Furthermore, Wang et al also observed the effect of SY0916 on the apoptosis of osteoclasts. The result showed that SY0916 between 0.01 and $10 \mu \mathrm{mol} / \mathrm{L}$ significantly decreased the lifespan of osteoclasts after treatment with IL-1 $\beta$. Therefore, the inhibitory effect of SY0916 on osteoclasts may be a critical pathway associated with its prevention of bone destruction.

The system constituted by RANKL, OPG, and RANK plays an important role in bone metabolism. RANKL and OPG are expressed by osteoblasts, whereas RANK is expressed by osteoclasts. RANKL and RANK affect bone metabolism by stimulating osteoclast differentiation, function and survival. In contrast, OPG is the decoy receptor for RANKL. OPG inhibits RANKL function by competing with RANK for RANKL ${ }^{[13,14]}$. In the case of increased levels of RANKL, patients present with symptoms characteristic of abnormal bone resorption, which appear similar to osteoporosis ${ }^{[15]}$. In the case of increased OPG levels, patients present with symptoms of hyperosteogeny or osteosclerosis. SY0916 directly inhibit the function of osteoclasts. Meanwhile, we further investigated the influence of SY0916 on gene expression of OPG, RANK, and RANKL. These results showed that SY0916 significantly inhibited IL-1 $\beta$-mediated increases in mRNA expression of RANKL and RANK in osteoblasts and osteoclasts, respectively. Noticeably, we found that the ratio of RANKL to OPG was significantly decreased, although OPG mRNA expression in osteoblasts was also decreased by SY0916. Therefore, we concluded that the mechanism underlying the effects of SY0916 on osteoclastic bone destruction involved regulation of the balance between RANKL and OPG, and the inhibition of RANK. 
It is well known that matrix metalloproteinase 9 (MMP9) is responsible for bone matrix degradation and is highly expressed both at early stages of osteoclast development and in mature osteoclasts. Moreover, many researchers have reported that RANKL stimulated MMP-9 gene expression in osteoclasts through TRAF6 ${ }^{[16]}$. In the present study, we found that SY0916 could inhibit the expression of MMP-9 induced by IL-1 $\beta$ at the level of both RNA and protein. The inhibitory effect of SY0916 on MMP-9 expression was in line with that of SY0916's effect on RANKL expression.

In conclusion, our study indicated that SY0916 could inhibit the inflammatory diseases associated with bone destruction by restoring the normal state of osteoclasts, which included the generation, activation, functioning and apoptosis of osteoclasts. In addition, the regulation of the RANKL-OPG-RANK system was also involved in this process. The regulation of a RANKL associated signal transduction network influenced protein expression that was associated with bone destruction, which included increases in MMP-9. In summary, this study is an important contribution to elucidating the mechanism underlying the effect of SY0916 on bone protection.

\section{Acknowledgements}

This work was supported by the National Natural Science Foundation of China (№ 30472033).

\section{Author contribution}

Wen-jie WANG and Lin WANG designed the research; Lin WANG, Shan-ying PENG, Ping LI, and Yang LIU performed the research; Lin WANG, Shan-ying PENG, and Ping LI analyzed the data; Lin WANG and Wen-jie WANG wrote the paper.

\section{Abbreviations}

RA, rheumatoid arthritis; CIA, collagen-induced arthritis; PAF, platelet-activating factor; $\mathrm{pOC}$, pre-osteoclast; $\mathrm{OCL}$, osteoclastlike cell; RANKL, receptor activator of NF-KB ligand; RANK, receptor activator of NF-KB; OPG, osteoprotegerin; TRAP, tartrate-resistant acid phosphatase; MMP-9, matrix metalloproteinases 9 .

\section{References}

1 Schett G, Teitelbaum SL. Osteoclasts and arthritis. J Bone Miner Res
2009; 24: 1142-6.

2 Väänänen HK, Laitala-Leinonen T. Osteoclast lineage and function. Arch Biochem Biophys 2008; 473: 132-8.

3 Zhu LY, Wang WJ, Huang HH, Lin ZY, Mou LY, inventors; Institute of Mataria Medica, Chinese Academy of Medical Sciences, Assignee. Araminone compounds, their preparations, pharmaceutical compositions and their use. PCT Patent, CN2005/001201, Jun 5, 2005.

4 Wang WJ, Wang L, Peng SY, Liu Y, Zhu LY, Huang HH, inventors; Institute of Mataria Medica, Chinese Academy of Medical Sciences, Assignee. A compound for the preparation of bone destruction inhibitor. CHN Patent, 200910086481.1, Jul 5, 2009.

5 Takahashi N, Udagawa N, Kobayashi Y, Suda T. Generation of osteoclasts in vitro, and assay of osteoclast activity. Methods Mol Med 2007; 135: 285-301.

$6 \mathrm{Kim}$ SN, Kim MH, Kim YS, Ryu SY, Min YK, Kim SH. Inhibitory effect of (-)-saucerneol on osteoclast differentiation and bone pit formation. Phytother Res 2009; 23: 185-91.

7 Akiyama T, Miyazaki T, Bouillet P, Nakamura K, Strasser A, Tanaka $\mathrm{S}$. In vitro and in vivo assays for osteoclast apoptosis. Biol Proced Online 2005; 7: 48-59.

8 Wei S, Kitaura H, Zhou P, Ross FP, Teitelbaum SL. IL-1 mediates TNFinducedosteoclastogenesis. J Clin Invest 2005; 115: 282-90.

9 Schmittgen TD, Livak KJ. Analyzing real-time PCR data by the comparative C(t) method. Nat Protoc 2008; 3: 1101-8.

10 Jimi E, Nakamura I, Duong LT, Ikebe T, Takahashi N, Rodan GA, et al. Interleukin-1 induces multinucleation and bone-resorbing activity of osteoclasts in the absence of osteoblasts/stromal cells. Exp Cell Res 1999; 247: 84-93

11 Nakamura I, Jimi E. Regulation of osteoclast differentiation and function by interleukin-1. Vitam Horm 2006; 74: 357-70.

12 Jimi E, Aoki K, Saito H, D'Acquisto F, May MJ, Nakamura I, et al. Selective inhibition of NF-kappa B blocks osteoclastogenesis and prevents inflammatory bone destruction in vivo. Nat Med 2004; 10: 617-24.

13 Li X, Ominsky MS, Stolina M, Warmington KS, Geng Z, Niu QT, et al. Increased RANK ligand in bone marrow of orchiectomized rats and prevention of their bone loss by the RANK Ligand inhibitor osteoprotegerin. Bone 2009; 45: 669-76.

14 Kobayashi Y, Udagawa N, Takahashi N. Action of RANKL and OPG for osteoclastogenesis. Crit Rev Eukaryot Gene Expr 2009; 19: 61-72.

15 Hofbauer LC, Zeitz U, Schoppet M, Skalicky M, Schüler C, Stolina M, et al. Prevention of glucocorticoid-induced bone loss in mice by inhibition of RANKL. Arthritis Rheum 2009; 60: 1427-37.

16 Sundaram K, Nishimura R, Senn J, Youssef RF, London SD, Reddy SV. RANK ligand signaling modulates the matrix metalloproteinase-9 gene expression during osteoclast differentiation. Exp Cell Res 2007; 313: 168-78. 